\title{
Cementitious adhesives for NSM carbon laminate strengthening system with treated surfaces
}

\author{
Reza Mohammadi Firouz, Eduardo N.B. Pereira, Joaquim A. O. Barros
}

ISISE, Institute of Science and Innovation for Bio-Sustainability (IB-S), Department of Civil Engineering, University of Minho, Guimarães, Portugal.

Contacting author: rezamf@civil.uminho.pt

\begin{abstract}
One of the main concerns of using structural composites as an effective technique for strengthening and rapid restoration of concrete structures is the behaviour of these systems in fire condition. Epoxy resins are currently used to bond structural composites to concrete substrate, but the vulnerability of their properties to high temperatures can compromise the strengthening effectiveness of these systems. Hence, finding an alternative adhesive is of a great importance. Recent studies presented promising results with the use of cement based materials as adhesives due to their good ability for transferring stresses and compatibility to the substrate. This study explores the adoption of a pre-treatment procedure for carbon fibre laminates for increasing the bond strength according to the near surface mounted (NSM) strengthening technique. Pull-out tests results confirmed the effectiveness of the proposed approach for enhancing the bond strength.
\end{abstract}

Keywords: FRP; Carbon laminate; NSM; Cement adhesive; Surface treatment.

\section{Introduction}

Strengthening and rehabilitation of structures are major issues worldwide. These interventions are due to several known reasons including calculation errors, alterations in building organization or functionalities, updating of design codes, loss of strength caused by deterioration and aging, and natural disasters, etc. [1]. As a result, restore and upgrading buildings and infrastructures are a worldwide necessity and one of the most prominent technical and scientific fields in civil engineering. Intense research and development on high performance and multifunctional construction materials have been carried out with the aim of constituting efficient systems for upgrading existing structures efficiently from the technical and economic point of views [2].

Fiber reinforced polymer (FRP) composites are one of these materials, today used for various applications, such as reinforcement for concrete structures in the form of passive or prestressed bars, stay cables, and newly built structures. Significant benefits of FRP composites such as low weight, corrosion resistance, high tensile strength and ease of handling have increasingly attracted the structural engineers' attention in recent years [3]. In construction industry, FRPs are most used in the repair and strengthening of existing structures. The near surface mounted (NSM) technique is one of the most effective FRP-based techniques for the flexural [4], shear [5], torsional [6] and punching [7] strengthening of reinforced concrete (RC) 
structures. According to the NSM technique, carbon fibre reinforced polymer (CFRP) reinforcements (in the form of laminates of rods) are installed into thin grooves executed in the concrete cover of the RC elements to be strengthened. Available research demonstrates that NSM is more efficient than the externally bonded reinforcing technique (EBR) for the strengthening of RC structures, regardless the concrete strength class [8].

A critical parameter when strengthening an existing structure is the choice of bonding material between the FRP and concrete surface. The use of polymeric epoxy as a bonding medium for the adherent has proven to give excellent stress transfer [2]. However, certain drawbacks can be identified when epoxy is used for bonding laminate to concrete substrate. In fact, they require a minimum application temperature, often $10^{\circ} \mathrm{C}$. Also, another concern of using polymeric adhesives in structural composites is the behaviour of these systems in fire condition. The vulnerability of epoxy resins in high temperatures is their main drawbacks. Hence, finding a matrix using an alternative material which can withstand the high temperatures until a certain level while preserving the mechanical performance, is of a great importance. To avoid some of these problems, the use of composite systems consisting of FRP elements and a cementitious bonding agent is suggested by various researchers [1-2,9]. The incombustibility of the cementitious materials is another reason to makes them a promising approach as a solution in this applications.

Besides the enhanced fire resistance, the high performance cement adhesive as a substitute of polymer-based adhesives should ensure adequate bond performance of FRPs to concrete substrate, present rheology characteristics for filling properly the relatively small volume of the groove, present the minimum possible shrinkage to avoid premature cracking, and be cured as faster as possible [10]. In this context, the current work focuses on introducing a simple and practical approach for pre-treatment of carbon laminates in order to improve their bond properties when a cement-based adhesive is used.

\section{Experimental works}

\subsection{Cementitious adhesive}

One of the practical concerns of using cementitious matrices as alternative adhesives for epoxy resins in CFRP reinforcement is complexity caused by usage of different ingredients in mixture design. Hence, using a ready commercial material simplifies the process of tailoring its properties in order to constitute an adhesive for FRP-based strengthening of RC structures. The adopted commercial product, herein designated by the virtual name SMT, is a 1-component, fibre reinforced, low shrinkage structural repair mortar meeting the requirement of class-R4 of EN 1504-3. It composed of sulphate resistant cement, selected aggregates (of maximum dimension $2.0 \mathrm{~mm}$ ) and additives. The SMT has the characteristics including, superior workability, suitable for hand and machine application, sulphate resistant, very low shrinkage behaviour and A1 fire rating, which can be applied up to $50 \mathrm{~mm}$ thick per application layer. It also does not require a bonding primer even when manually applied. According to the manufacturer, the SMT has the properties indicated in Table 1. For producing the aimed cement based adhesive, herein designated by CBA_UM1, different mixtures of SMT have been prepared and tested to reach good characteristics in terms of strength, flowability, and shrinkage behaviour. Since workability is an important issue in case of NSM strengthening due to the small dimensions of the groove, compatible superplasticizer has been added to the mixture. Average compressive and flexural strength of CBA_UM1 were $35.6 \mathrm{MPa}$ and $7.5 \mathrm{MPa}$, respectively.

In the present work, a series of tests have been conducted on implementing CBA_UM1 with the CFRP laminates in NSM strengthening technique to evaluate the bonding behaviour of these materials. After some preliminary characterization tests, the material mixture has been modified to reach the desired followability and minimum shrinkage. In addition to that, a pre-treatment process on the adopted CFRP laminate and on the concrete substrate surfaces by increasing the roughness their surfaces in an attempt of improving the bond 
between the CBA_UM1 and the both treated CFRP laminate and concrete substrate.

Table 1. Properties of SMT according to the supplier

\begin{tabular}{cc}
\hline Characteristic & Description \\
\hline Appearance/Color & Grey powder \\
\hline $\begin{array}{c}\text { Fresh mortar } \\
\text { density }\end{array}$ & $\sim 2.05 \mathrm{~kg} / \mathrm{l}$ \\
\hline Grading & $\mathrm{D}_{\text {max }}: 2.0 \mathrm{~mm}$ \\
\hline Pot-life & $\mathrm{At}+20^{\circ} \mathrm{C}: \sim 45$ minutes \\
\hline
\end{tabular}

\subsection{Pre-treatment of laminates}

S\&P Carbon laminates with cross section of $1.4 \times 10$ $\mathrm{mm}^{2}$, supplied by Clever Reinforcement, were used in this work. The tensile strength and modulus of elasticity for the carbon strips were $2050 \mathrm{MPa}$ and $170 \mathrm{GPa}$ respectively. These CFRP laminates are generally used as smooth surfaced reinforcements which led to a minimum grip between the laminate and adhesive. Researches proved the effectiveness of physical bond improvement on maximum pullout load capacity [11]. For increasing the roughness of the CFRP laminate surfaces, and consequently an interlock resisting mechanisms between this type of laminate and the CBA_UM1, two types of sands, Sika Carga2 ${ }^{\mathrm{TM}}$ with the maximum particle size of $0.2 \mathrm{~mm}$, and a normal fine sand with the particle size range of 0.6 to $0.85 \mathrm{~mm}$ were used for covering these surfaces. The sands were glued to the CFRP's surfaces using $S \& M^{\circledR} 55$ epoxy resin. After a recommended 7 days of curing they were considered ready for being bonded with the CBA_UM1 according to the NSM technique. In order to standardize the process, the laminates were weighted with an accuracy of 0.001 grams in the three following stages (Figure 1): before any treatment (as received), after applying the resin, and after adding the Carga2 or fine sand. 32 CFRP laminates have been treated with the same procedure, and the ones with the minimum weight variation were selected for strengthening process. The standard deviation of the added weights between laminates was around $0.5 \%$.

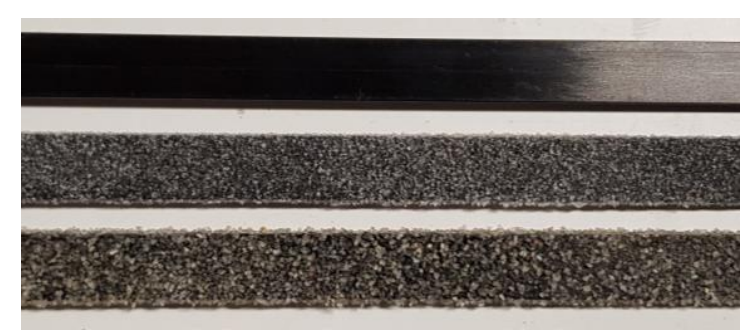

Figure 1. Surface configuration of CFRP laminates: (top) untreated, (middle) treated with Carga2 (bottom) treated with fine sand

A further attempt of improving the bond provided by CBA_UM1, another series of pull out tests was carried out by treating the walls of the groove. For this purpose, the internal surfaces of the groove were initially covered with a layer of $S \& M^{\circledR} 55$ epoxy resin. Immediately the groove was filled with same sand as used for the treatment of the laminate surfaces, and after 24 hours, when the resin was hardened, the sand not bonded to the groove's walls was removed (Figure 2).
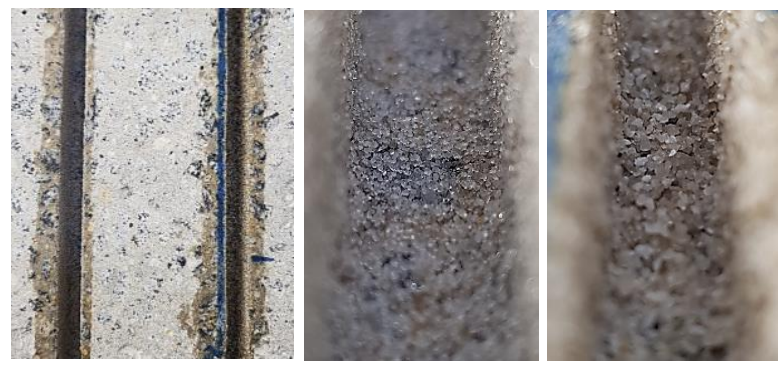

Figure 2. Treatment of concrete substrate: (left) grooves treated with sand; (center) Carga 2 treated groove; (right) Fine sand treated groove

\section{Pull-out tests}

\subsection{Installation of CFRP strips}

Grooves of $10 \mathrm{~mm}$ width by $20 \mathrm{~mm}$ depth were executed in concrete specimens at the age of 60 days. Figure 3 shows the insertion process of the carbon fiber laminates into the grooves. After placing a small amount of CBA_UM1 into the groove, the laminate was inserted, then the groove was filled and at last, the excess adhesive was removed from the surface Aluminium plates were used as spacers to hold the laminates in position. The procedure was repeated in the same way for the second groove in the concrete block. 

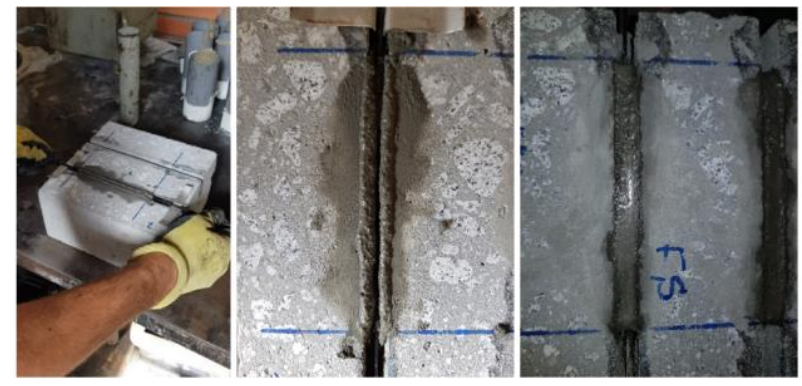

Figure 3. Process of introducing CFRP laminates into the grooves from left to right

Table 2 presents the details of strengthened samples with respect to type of surface treatments. For comparison purpose a sample with non-treated laminate was also tested. The bond length for all the tested specimens was $125 \mathrm{~mm}$.

Table 1. Strengthening details of samples

\begin{tabular}{ccc}
\hline Label & $\begin{array}{c}\text { Treatment } \\
\text { material }\end{array}$ & Pre-treatment \\
\hline P-NT & N/A & N/A \\
\hline FS-TLS & Fine Sand & Laminate \& Substrate \\
\hline C2-TLS & Carga2 & Laminate \& Substrate \\
\hline FS-TL & Fine Sand & Laminate \\
\hline C2-TL & Carga2 & Laminate \\
\hline
\end{tabular}

A period of three weeks was adopted for curing the CBA_UM1 after its introduction into the groove. Compressive tests with samples of CBA_UM1 at different ages showed that marginal increase of compressive strength was occurred between 14 and 28 days. The pull-out specimens were then placed in the curing chamber at about $23^{\circ} \mathrm{C}$ and $60 \%$ of relative humidity before testing. After performing the tests, the concrete samples were cut in the transversal direction which confirmed that the adhesive was filled properly the groove, owing to the proper flowability of the cementitious matrix mixture.

\subsection{Pull-out test setup}

Concrete prisms of $200 \times 200 \times 100 \mathrm{~mm}$ and C30 strength class according to Eurocode 2 code were prepared for installing the NSM strengthening system. In each prism two grooves were executed according to the schematic representation shown in Figure 4. Three identical specimens were prepared and tested for each series. Figure 4 shows the test setup for pull-out tests, and Figure 5 is its schematic representation with more details. Five linear variable differential transformers (LVDT) were used to record the data, two of them used for loaded and free end slips, and the remaining have the purpose of recording displacements in the transversal direction. The applied force was recorded with a $50 \mathrm{kN}$ load cell. The test was displacement controlled in the servo-hydraulic actuator imposing a displacement rate of $2 \mu \mathrm{m}$. Two LVDTs installed vertically (illustrated in Figure 5) were used to monitor the displacements on the direction, perpendicular to the loading direction.

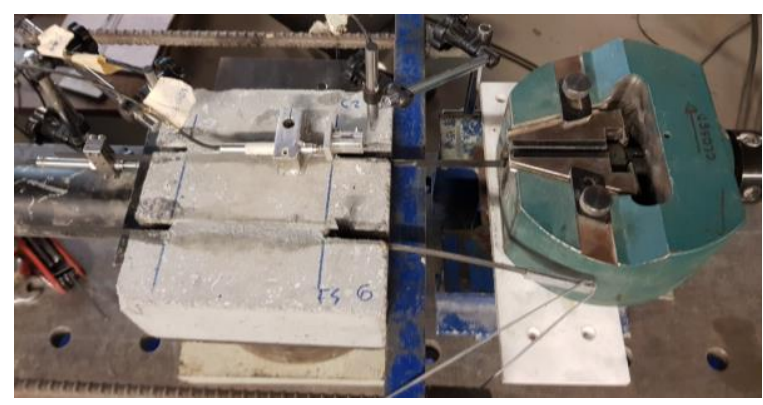

Figure 4. Photo of pull-out tests with NSM CFRP laminates

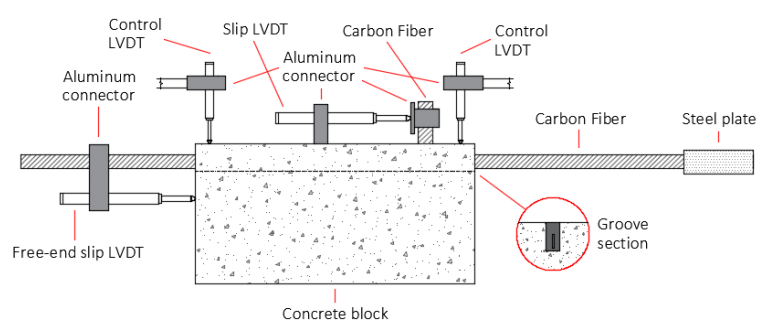

Figure 5. Schematic representation of the pull-out test setup

\section{Results and discussion}

Figure 6 shows the pull-out force for all tested series. It indicates the higher ability of Carga2 treatment approach, to increase the maximum pull-out force. The relevant obtained results are presented in Table 3. The average recorded value for displacement from two control LVDTs, positioned vertically in the direction perpendicular to the direction of applied load, was about $0.4 \mathrm{~mm}$ for all samples which is about $0.4 \%$ of the dimension of the concrete block in the same direction. 
Table 2. Pull-out test results

\begin{tabular}{cccccc}
\hline Label & $\begin{array}{c}\text { Pull- } \\
\text { out } \\
\text { force } \\
\text { [KN] }\end{array}$ & $\begin{array}{c}\text { Load- } \\
\text { end } \\
\text { Slip at } \\
\text { max } \\
\text { force } \\
\text { [mm] }\end{array}$ & $\begin{array}{c}\text { Free- } \\
\text { end } \\
\text { slip at } \\
\text { max } \\
\text { force } \\
\text { [mm] }\end{array}$ & $\begin{array}{c}\text { Avg. } \\
\text { Pull- } \\
\text { out } \\
\text { force } \\
\text { [KN] }\end{array}$ & $\begin{array}{c}\text { Avg. } \\
\text { bond } \\
\text { strength } \\
\text { [MPa] }\end{array}$ \\
\hline P-NT & 1.44 & 0.06 & 0.01 & 1.44 & 0.51 \\
\hline \multirow{2}{*}{ FS-TLS } & 12.64 & 0.53 & 0.04 & & \\
& 13.64 & 0.44 & 0.07 & 13.53 & 4.75 \\
& 14.32 & 0.57 & 0.37 & & \\
\hline \multirow{2}{*}{ C2-TLS } & 10.98 & 0.47 & 0.10 & & \\
& 13.61 & 0.54 & 0.07 & 13.73 & 4.82 \\
& 16.62 & 0.76 & 0.11 & & \\
\hline \multirow{3}{*}{ FS-TL } & 10.99 & 0.52 & 0.09 & & \\
& 14.72 & 0.43 & 0.10 & 14.01 & 4.92 \\
& 16.32 & 0.61 & 0.05 & & \\
\hline \multirow{3}{*}{ C2-TL } & 14.06 & 0.56 & 0.03 & & \\
& 17.64 & 0.68 & 0.14 & 16.90 & 5.93 \\
& 19.01 & 0.73 & 0.24 & & \\
\hline
\end{tabular}

The results clearly confirm the substantial effectiveness of the proposed surface pretreatment procedure. The pre-treatment could increase the average bond strength between 9 to same performance in case of maximum pull-out force capacity.

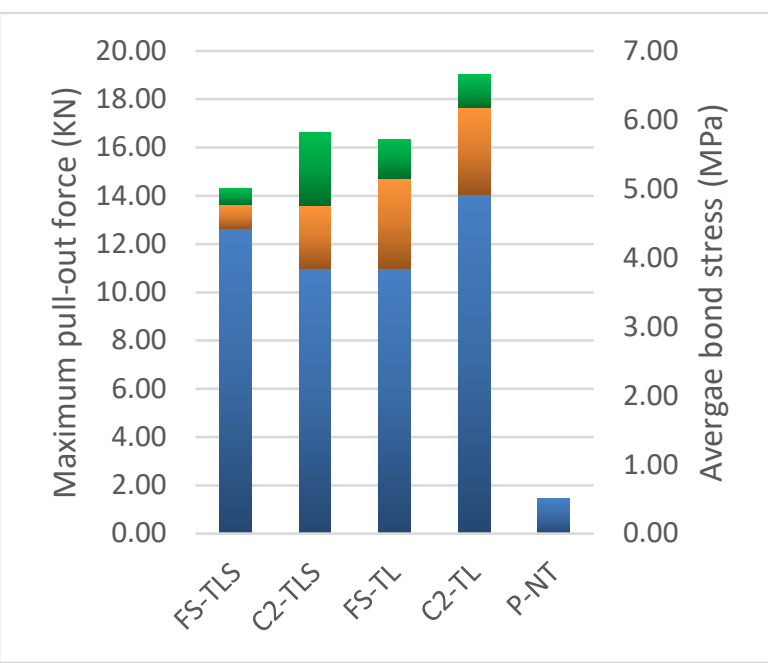

Figure 6. Pull-out force for different test series

The laminates which coated with a layer of fine sand had rougher surfaces comparing those that treated with Carga2. However, results indicate that treatment with Carga2 is more effective in improving bond strength. Better performance of the Carga2 treatment could be related to the better

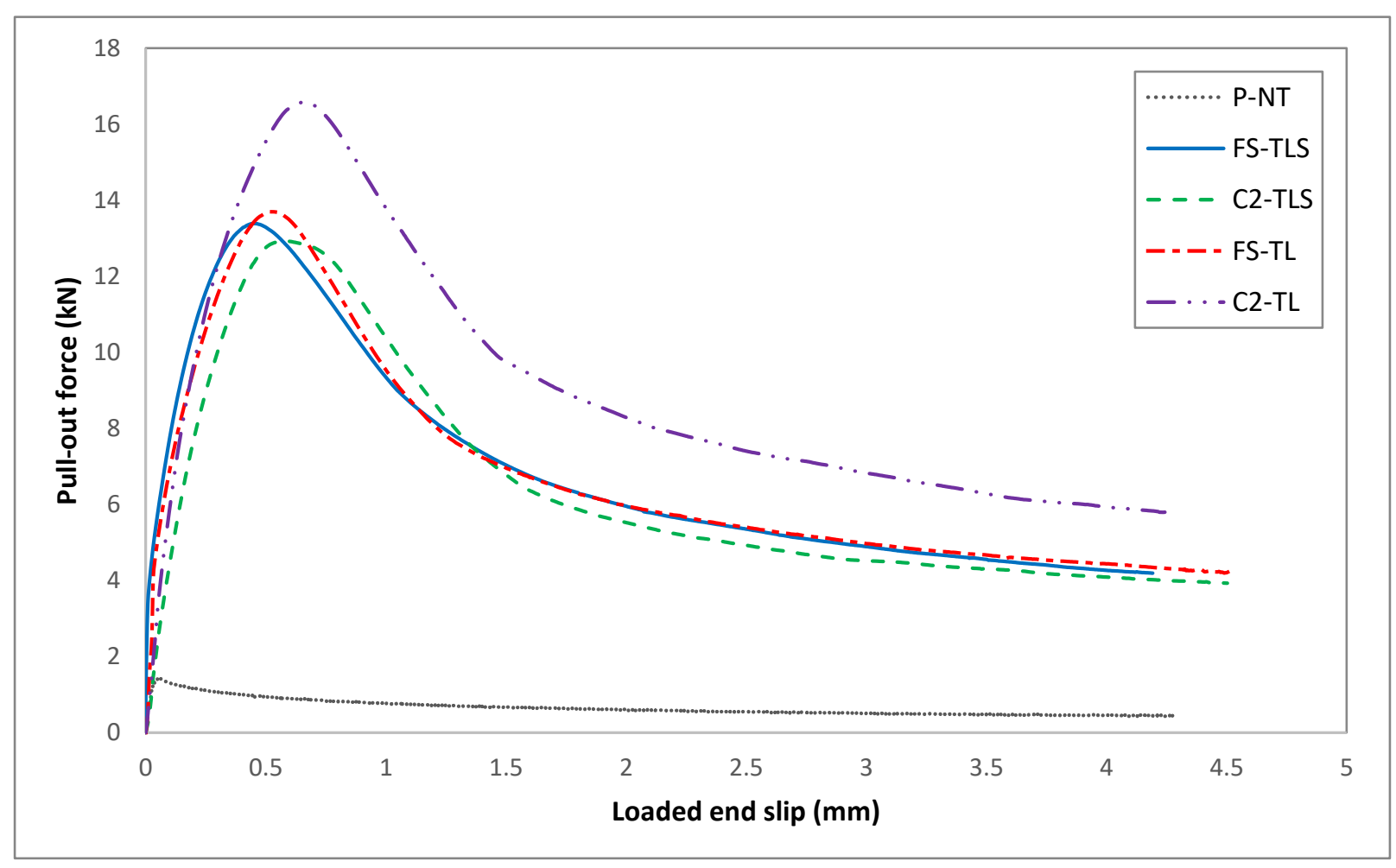

Figure 7. Pull-out force vs. loaded end slip for the tested series

11 times of the untreated specimens. However, despite C2-TL, other series showed almost the distribution of the grips (interlock resisting 
mechanisms) on laminates' surfaces due to their smaller particle size.

All the specimens have failed by slippage of the CFRP laminate. Hence, despite the significant increase on the peak pull-out force ensured by the adopted treatments for the laminate and groove surfaces, they were not sufficiently effective to mobilize the tensile capacity of the laminate. For similar bond length, concrete strength class and original CFRP laminate, slippage was also the observed failure mode when using epoxy adhesive, but the maximum average bond strength was higher (about $10 \mathrm{MPa}$ ), as well as its corresponding loaded end slip (1.13 $\mathrm{mm}$ ) [12]. The results indicate that in general, Carga2 treatment was $11 \%$ more effective than fine sand treating.

Figure 7 shows the pull-out force versus loaded end slip for the tested series (each curve is the average of the three specimens composing a series). The graphs clearly show the difference between plain and pre-treated laminates which validates the effectiveness of the approach. Also, initial stiffness and slip at pick load were slightly higher in Carga2 treatment.

\section{Conclusions}

In an attempt of improving the bond effectiveness when using a cement based adhesive (CBA) for bonding NSM CFRP laminates, two strategies were adopted: 1) treatment of the surfaces of the CFRP laminate with fine sand; 2 ) treatment of both the surfaces of the CFRP laminate and the walls of the groove. The treatment was applied in the bond length and two types of fine sand were adopted (C2 and FS). From the pull-out tests it was verified that the adopted treatment strategies were able of increasing 9 to 11 times the maximum pull-out force, but not sufficient to mobilize the tensile strength of the CFRP laminates, since all the tested specimens failed by slippage. For the adopted cement based adhesive, the commercial fine sand (C2) was more effective, mainly when the treatment was restricted to the surfaces of the CFRP laminate. In any case the average bond strength was limited to $6 \mathrm{MPa}$, while values close to $10 \mathrm{MPa}$ were registered when using epoxy adhesive with untreated CFRP laminates [12].
Further improvements are being implemented in this first generation of CBA in order to be capable of mobilizing the tensile capacity of the adopted CFRP laminates. Assessing the enhancements this CBA will provide to the bond performance when submitted to high temperature (by comparison to the use of epoxy adhesive) is an ongoing task in this research project.

\section{Acknowledgements}

The Authors acknowledge the support provided by FCT through the PTDC/ECM-EST/1882/2014 project. The collaboration of Sika is also acknowledged.

\section{References}

[1] Hashemi S., Al-Mahaidi R., Cement based bonding material for FRP, 11th International Inorganic-Bonded Fiber Composite Conference, IIBCC, Madrid, Spain; 2008.

[2] Talisjen B., Blanksvard T., Mineral-Based Bonding of Carbon FRP to Strengthen Concrete Structures, Journal of Composites for Construction. 2007; 11(2): 120-128.

[3] Mohammadi Firouz R., Effect of Carbon and Glass FRP Confinement on Compressive Strength of Pre-Damaged Concrete Cylinders, Master thesis: Sharif University of Technology. Iran; 2011.

[4] Dalfré, G.M.; Barros, J.A.O., NSM technique to increase the load carrying capacity of continuous RC slabs, Engineering Structures Journal, 2013; (56): 137-153.

[5] Dias, S.J.E.; Barros, J.A.O., NSM shear strengthening technique with CFRP laminates applied in high $\mathrm{T}$ cross section $\mathrm{RC}$ beams, Composites Part B Journal, 2017; (114): 256-267.

[6] Gowda, C.C.; Barros, J.A.O.; Guadagnini, M., Experimental study of torsional strengthening on thin walled tubular reinforced concrete structures using NSMCFRP laminates, Composite Structures Journal, 2019; (208): 585-599.

[7] Barros, J.A.O.; Rezazadeh, M.; Laranjeira, J.P.S.; Hosseini, M.R.M.; Mastali, M.;

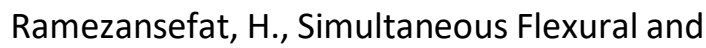


Punching Strengthening of RC Slabs according to a New Hybrid Technique Using U-Shape CFRP Laminates, Composite Structures Journal, 2017; (159): 600-614.

[8] Sena-Cruz J., Barros J., Bond Behavior of Carbon Laminate Strips into Concrete by Pullout-Bending Tests, $3^{\text {rd }}$ International symposium of Bond in Concrete, Budapest, 2002.

[9] Hashemi S., Al-Mahaidi R., Investigation of Bond Strength and Flexural Behaviour of FRP-Strengthened Reinforced Concrete Beams Using Cement-Based Adhesives, Australian Journal of Structural Engineering, 2010; 11(2).

[10] Mohammed A., Al-Saadi N., Al-Mahaidi R., Bond behavior between NSM CFRP strips and concrete at high temperature using innovative high-strength self-compacting cementitious adhesive (IHSSC-CA) made with graphene oxide, Construction and Building Materials. 2016; (127): 872-883.

[11] Katz A., Berman N., Bank L.C., Effect of high temperature on bond strength of FRP rebars, Journal of Composite Construction, 1999; 3(2): 73-81.

[12] Sena-Cruz J.M., Barros J.A.O., Azevedo A.F. M., Gettu R., Bond behavior of near-surface mounted CFRP laminate strips under monotonic and cyclic loading, ASCE Composites for Construction Journal, 2006; 10(4): 295-303. 